\title{
BMJ Global Health Perceptions of the quality of generic medicines: implications for trust in public services within the local health system in Tumkur, India
}

\author{
Praveen Kumar Aivalli, ${ }^{1}$ Maya Annie Elias, ${ }^{1}$ Manoj Kumar Pati, ${ }^{1}$ \\ Srinath Bhanuprakash, ${ }^{1}$ Chikkagollahalli Munegowda, ${ }^{1}$ Zubin Cyrus Shroff, ${ }^{2}$ \\ Prashanth N Srinivas ${ }^{1}$
}

To cite: Aivalli PK, Elias MA Pati MK, et al. Perceptions of the quality of generic medicines: implications for trust in public services within the local health system in Tumkur, India. BMJ Glob Health 2018;2:e000644. doi:10.1136/ bmjgh-2017-000644

Handling editor Seye Abimbola

- Additional material is published online only. To view, please visit the journal online (http://dx.doi.org/10.1136/ bmjgh-2017-000644).

Received 11 November 2017 Revised 19 November 2017 Accepted 24 November 2017

CrossMark

${ }^{1}$ Institute of Public Health, Bangalore, Karnataka, India ${ }^{2}$ Alliance for Health Policy and Systems Research, World Health Organization, Geneva, Switzerland

Correspondence to Dr Prashanth N Srinivas; prashanthns@iphindia.org

\section{ABSTRACT}

Introduction Generic medicines are an important policy option to reduce out-of-pocket expenditure on medicines. However, negative perceptions of their quality affect utilisation and raise issues of confidence and trust in medicines and health services. The aim of the study was to test the quality of generic and branded medicines and explain negative perceptions towards generic medicines. Methods The study was part of a larger study on access to medicines. Information on various quality parameters was collected for branded medicines and branded and unbranded generic versions of the same medicines from government and private pharmacies in Karnataka in Southern India. To assess perceptions related to quality and drivers of preferred point of care (public vs private), focus group discussions were conducted with diabetes and hypertension patients, health workers and private pharmacists. The results of the quality tests were assessed and thematic analysis was conducted on the qualitative data to develop a conceptual framework to explain perceptions of medicine and care quality in the local health system.

Results The generic and branded variants of the medicines tested were of comparable quality. Contrary to the quality test results, patients' and health workers' perceptions of quality were largely in favour of branded medicines. Negative perceptions of medicine quality along with other drivers contribute towards choosing more expensive medicines in the private sector. Trust in the health system emerged as an underlying central theme that explained and drove choice of medicines and providers within the local health system. Conclusion Negative perceptions of generic medicines and preferential promotion of branded medicines over generics by pharmaceutical companies could influence prescriber behaviour and affect trust in healthcare provided in public services. To succeed, access to medicines programmes need to systematically invest in information on quality of medicines and develop strategies to build trust in healthcare offered in government health services.

\section{BACKGROUND}

Ensuring equitable access to essential medical products, vaccines and technologies of assured

\section{Key questions}

What is already known about this topic?

- The use of generic medicines is steadily increasing worldwide. However, negative perceptions about their quality remain.

What are the new findings?

- Negative perceptions towards generic medicines affect their usage, and raise questions of confidence in medicines as well as in healthcare providers prescribing and dispensing these medicines.

- If perceptions that are unfounded in empirical evidence are allowed to persist, they can negatively influence the utilisation of services in government health centres.

- Patient perceptions are one of the important drivers contributing to patients choosing expensive care in the private sector over comparable care in government health centres.

Recommendations for policy

- Policies and programmes that seek to improve medicine availability, particularly generic medicine availability, need to invest in building trust in medicine quality (as well as care) in government health facilities.

quality, safety, efficacy and their scientifically sound and cost-effective use is an important function of a well performing health system. ${ }^{1}$ India has been referred to as the pharmacy of the low-income and middle-income world. ${ }^{2}$ India's pharmaceutical industry is the third largest globally in terms of volume of medicines exported. ${ }^{3}$ However, several essential medicines remain inaccessible within India especially for the poor, due to policy and implementation failures in ensuring access. ${ }^{45}$

As in many other low-income and middle-income countries, healthcare in India 
is provided through public and private providers; services provided in government health facilities are either free of cost (primary healthcare) or with nominal user fees at the point of service delivery in secondary and tertiary settings for most of the population and for most services.

In the private sector, payments are generally fee for service made through out-of-pocket (OOP) payments at the point of service delivery. ${ }^{6}$ Recent efforts through insurance schemes remain fragmented both in terms of services provided and segments of the population covered; similarly conditional cash transfers and strategic purchasing are limited to priority services like immunisation, maternal and child health services for poor and vulnerable populations and for some secondary and/or tertiary conditions. In most instances, expenditure on medicines is not covered.

OOP expenditure on medicines alone is estimated to be $86 \%$ of all OOP expenditure and is a known driver of poverty among the Indian poor. ${ }^{7-10}$ There is no systematic universal health coverage plan in most states despite advocacy efforts and campaigns. ${ }^{71}$ Most government health facilities in the country procure unbranded generic medicines with international non-proprietary name labelling, ${ }^{12}{ }^{13}$ whereas private pharmacies typically stock and sell branded proprietary medicines or branded generic equivalents. Concerns about quality of medicines have been expressed by several authors worldwide, ${ }^{14-21}$ this is especially true regarding medicines manufactured in India, ${ }^{22-24}$ and even more so, regarding the quality of generic medicines. ${ }^{25-27}$

Although perceptions about the quality of generic medicines have improved, mistrust remains, often reflected by assertions such as "(the) more you pay, better the quality". ${ }^{28}$ Medicines are a crucial building block of the health system and contribute to health and well-being of individuals and populations. Negative perceptions that are unfounded in empirical evidence, if unaddressed, can negatively influence utilisation of health services, particularly in the public sector. ${ }^{29-33}$

\section{Trust and health-seeking behaviour}

Health-seeking behaviour is influenced by various factors including patient satisfaction, competence of provider, perceived quality of care and patient experience, which in turn are affected by trust in the care provided. ${ }^{31}$ Trust in health systems and services is multidimensional and is conditioned by macrolevel factors such as health policy and overall public opinion about health providers and microlevel factors including individual perceptions and experience ${ }^{31}$ Vulnerability resulting from the experience of being ill often requires patients to place their trust in a trustee (in this case a healthcare provider), in the expectation of amelioration or cure. A positive result from this experience tends to facilitate the building of a trustful relationship which conditions future encounters. ${ }^{32} 33$

In the case of government health services, lack of trust can affect utilisation and in turn drive patients to the private sector, increasing OOP expenditures. In the case of non-communicable diseases (NCDs), the need for long-term and often lifelong treatment is associated with particularly high OOP spending. ${ }^{34}{ }^{35}$ Patients with higher ability to pay for medicines are likely to continue taking medicines longer while poorer patients tend to forego or shorten treatment. Lowering medicine cost or providing medicines as a part of a universal health coverage strategy can improve treatment adherence, outcomes and improve quality of life. ${ }^{1135}$

To improve access to generic medicines, the Indian Government launched the Janaushadhi campaign (people's medicine in Hindi) in 2008 to provide quality, appropriately priced generic medicines in the country through a proposed countrywide chain of generic medicine stores. ${ }^{36}{ }^{37} \mathrm{~A}$ few studies have investigated the quality of generic medicines provided at such outlets and found generic medicines to be of similar quality to their branded equivalents. ${ }^{38-40}$ However, wider systemic issues related to trust in public services and providers and how these could affect the utilisation of such schemes or services, are scarcely studied. ${ }^{41}$ Current policies and interventions consider access to medicines as largely consisting of issues related to streamlining supply and availability, which provides only a partial view. On the other hand, an examination of the systemic issues related to healthcare provider and community perceptions of medicines and trust helps situate the problem of access to medicines within the wider health system. ${ }^{1}$

In this paper, our objective is to understand people's perceptions of generic medicines quality and assess how these perceptions affect access to medicines in government health facilities. We develop a framework to explain the role of trust in access to medicines and identify ways in which trust influences access to medicines in a local health system using focus group discussions (FGD) and in-depth interviews with patients and health workers. We also assess the quality of generic and branded equivalents of essential medicines $^{\mathrm{i}}$ for treating selected NCDs in a South Indian district.

\section{METHODS}

The study uses data collected under the Access to Medicines Research Project implemented by the Institute of Public Health, Bangalore with support from the Alliance for Health Policy and Systems Research, WHO. The study has been registered with the Clinical Trials Registry of India with registration identifier number CTRI/2015/03/005640. This paper presents findings from the Pre-Results phase of the study. The full study protocol describing the details of the study design, methodology and tools has been published earlier. ${ }^{42}$

\section{Data collection and study setting}

The study was conducted in Tumkur district of Karnataka in Southern India. Tumkur is one of the 30 districts

${ }^{\mathrm{i}}$ National List of Essential Medicines 2015, India, WHO. 
Table 2 Details of FGDs conducted with health workers and private pharmacists

\begin{tabular}{|c|c|c|c|c|c|c|}
\hline \multirow[b]{2}{*}{ FGD } & \multirow[b]{2}{*}{ Participants } & \multirow[b]{2}{*}{ Age group (years) } & \multirow[b]{2}{*}{ No. of participants } & \multirow[b]{2}{*}{ Experience in years } & \multicolumn{2}{|c|}{ Gender of the participant } \\
\hline & & & & & Male & Female \\
\hline 1 & Community health & $30-40$ & 7 & $3-5$ & 0 & 7 \\
\hline 2 & workers & $30-40$ & 8 & $5-10$ & 0 & 8 \\
\hline 3 & & $25-40$ & 7 & $5-10$ & 0 & 7 \\
\hline 4 & Private pharmacists & $30-40$ & 12 & $7-20$ & 11 & 1 \\
\hline
\end{tabular}

FGD, focus group discussion.

of Karnataka. With a population of 2.6 million, it is one of the larger districts in the state. Each district is further divided into administrative subunits called talukas. Three non-contiguous talukas were selected for the study.

To understand health-seeking behaviour and perceptions related to medicine quality, we conducted FGDs and in-depth interviews as described below. For testing quality of medicines, we sampled branded and generic NCD medicines from government and private pharmacies. Full details of the study design and tools are provided in the paper based on the study protocol. ${ }^{42}$

\section{Focus group discussions}

FGDs were conducted with patients, health workers and private pharmacists. Patient FGDs were conducted with the objective of understanding their awareness of generic medicines, their perspectives on quality of medicines, patient experience and identifying barriers in accessing care at primary health centres (PHCs), particularly for patients with NCDs. To cover a wide range of perspectives, we ensured diverse representation of gender and socioeconomic categories across the FGDs.

For the health worker FGDs, we invited two categories of health workers working at the PHC level, the Accredited Social Health Activist, who is a village-level health worker catering to basic health needs at the village level and the Auxiliary Nurse-Midwife, who is in charge of a subcentre that caters typically to 5000 people (approximately three to five villages). Health worker FGDs were conducted with the objective of understanding health workers' experiences and challenges in delivering NCD

Table 1 Details of FGDs conducted with patients with NCDs

\begin{tabular}{lllcl}
\hline & & & \multicolumn{2}{c}{$\begin{array}{l}\text { Gender of the } \\
\text { participants }\end{array}$} \\
\cline { 4 - 5 } FGD & $\begin{array}{l}\text { Age group } \\
\text { (years) }\end{array}$ & $\begin{array}{l}\text { No. of } \\
\text { participants }\end{array}$ & Male & Female \\
\hline 1 & $30-40$ & 13 & 7 & 6 \\
\hline 2 & $30-40$ & 16 & 12 & 4 \\
\hline 3 & $40-50$ & 12 & 6 & 6 \\
\hline 4 & $40-60$ & 11 & 6 & 5 \\
\hline 5 & $40-60$ & 10 & 5 & 5 \\
\hline 6 & $40-60$ & 12 & 6 & 6 \\
\hline
\end{tabular}

FGD, focus group discussion; NCD, non-communicable disease. care to rural communities. For the FGDs with private pharmacists, we approached the district-level pharmacists' association and invited pharmacists from Tumkur city through an open invitation to all its members.

For FGDs and in-depth interviews, an information sheet in Kannada (the state's official language) was provided and informed consent obtained. Two researchers conducted the FGDs; one facilitated the discussion and the other took notes and audio recorded the discussions. The duration of the FGDs ranged from 60 to 90 minutes. Details of FGDs are provided in tables 1 and 2. We explored participants' perceptions of price and quality of medicines supplied both in government and private pharmacies and also their perceptions of generic medicines, medicine quality and regulation.

The following are some of the questions used to initiate discussion among participants in the patient and health worker FGDs.

1. Where do you go when you are ill? And why?

2. Describe what you feel about the quality of medicines?

3. Describe your experience with government (generic) and branded medicines?

4. Why do people prefer to go to private doctors when government services are free of cost?

In-depth interviews

Semi-structured in-depth interviews were conducted with PHC doctors, pharmacists and district health managers with the objective of exploring their perceptions of the quality of generic and branded medicines and to explore how these perceptions influence their interaction with patients and/or prescription practices. For these interviews, we selected one district health manager, four PHC doctors (two men and two women) with five or more years of work experience and two pharmacists (both women) from the study talukas. All in-depth interviews were tape recorded, transcribed and translated into English for analysis.

\section{Sampling for drug testing}

We sampled medicines from three sampling points: district hospital (government), private pharmacy and Janatha Bazaar (JB). JB in Kannada is people's market. It is an initiative of the Karnataka government in line with the Indian government's pharmaceutical department-led Janaushadhi, but operated by the Karnataka State Cooperative Consumer Federation, a state government 
established federation of cooperative societies, whose main purpose is procurement and sale of products (including medicines in the case of JBs) at fair prices. JB's typically procure and sell low-cost medicines at or near cost price. Most JBs are situated within or near large district-level or state-level hospitals.

For medicine sampling at the district hospital, we approached the district hospital pharmacy for collecting the required samples. For private pharmacy sampling, we selected a busy private pharmacy situated near the district hospital. For JB samples, we chose a JB within the premises of a large teaching hospital in the state capital, Bangalore. The choice of sampling points for drug testing covered the three most used types of pharmacies in both the public and private sectors in Karnataka.

Based on the most recent version of the Standard Treatment Guidelines (STGs) for diabetes and hypertension developed by the National Health Mission (NHM), India, we shortlisted 11 medicines namely, hydrochlorthiazide $50 \mathrm{mg}$, atenolol $50 \mathrm{mg}$, enalapril $10 \mathrm{mg}$, losartan $50 \mathrm{mg}$, amlodipine $5 \mathrm{mg}$, atorvastatin $10 \mathrm{mg}$, glibenclamide $5 \mathrm{mg}$, metformin $500 \mathrm{mg}$, pioglitazone $1 \mathrm{mg}$, glimiparide $1 \mathrm{mg}$ and injectable insulin. Based on frequent prescription and inclusion in STGs for first-line management of diabetes and hypertension, we selected 4 drugs from the 11 shortlisted earlier. For diabetes, we selected metformin hydrochloride (available as a $500 \mathrm{mg}$ tablet) and glibenclamide (available as a $5 \mathrm{mg}$ tablet). For hypertension, we selected atenolol (available as a $50 \mathrm{mg}$ tablet) and amlodipine besylate (available as a $5 \mathrm{mg}$ tablet). Private pharmacies were selling these medicines under various brand names with different prices. Under the assumption that there may be a quality difference between the most widely used drug (most sold) and the least expensive (possibly a branded or unbranded generic version of the most sold), we selected both medicine variants from private pharmacies. JB had two drug counters, one for branded medicines and another for generic variants. Doctors and patients generally identified the latter counter as the 'generic medicines' counter. Samples were collected from both these counters. All samples were checked for manufacture and expiry dates. Medicines with at least oneyear to the expiry date were selected for the test. Details of samples collected from different sources and blinding process are provided in table 3 .

\section{Sample collection and blinding process of medicines}

Time, date, batch number and other relevant details were noted on the receipt along with the signature of the pharmacist for all the medicine samples. For each medicine, 300 tablets (units) were sampled from each source; 150 tablets for the government laboratory and 150 tablets for the private laboratory. Before sending the medicines for quality tests, samples were blinded using non-reactive adhesive papers and coded accordingly. Samples were then packed into polythene covers and stored in airtight containers before dispatch to the laboratories. These samples were sent to two laboratories for detailed analysis. Medicines reached the laboratory within 48 hours of procurement. One set was sent to the Karnataka State Drugs Control Department's testing laboratory in Bangalore, Karnataka. It is a statutory laboratory that carries out testing and analysis of samples of drugs drawn by enforcement officers and samples sent by a purchaser. To validate the results, another set of samples from the same batch was sent to a private laboratory outside Karnataka selected from a list of such laboratories certified by the Central Drugs Standard Control Organization (CDSCO). The CDSCO is a government regulatory body that provides a full list of certified private laboratories on their website.

\section{Details of tests performed}

For the medicine quality tests, methods prescribed in the Indian Pharmacopoeia (IP), 2014 as per the standards laid down under the Drugs and Cosmetics Act 1940 and Rules 1945 were followed.

The following tests were performed at both the government and private laboratories:

1. Identification test: to establish the identity of the molecule using high-pressure liquid chromatography (HPLC) or infrared spectroscopy as per the method prescribed for each medicine.

Table 3 Details of samples of medicines collected from different sampling points

\begin{tabular}{|c|c|c|c|c|c|c|}
\hline \multirow[b]{3}{*}{$\begin{array}{l}\text { Serial } \\
\text { number }\end{array}$} & \multirow[b]{3}{*}{ Name of the molecule } & \multicolumn{5}{|c|}{ Source and number of samples collected from each source } \\
\hline & & \multirow[b]{2}{*}{$\begin{array}{l}\text { Government } \\
\text { district } \\
\text { hospital } \\
\text { (tablets in } \\
\text { numbers) }\end{array}$} & \multicolumn{2}{|c|}{ Private pharmacy } & \multicolumn{2}{|l|}{ Janatha Bazar } \\
\hline & & & $\begin{array}{l}\text { Most sold } \\
\text { (tablets in } \\
\text { numbers) }\end{array}$ & $\begin{array}{l}\text { Least } \\
\text { expensive } \\
\text { (tablets in } \\
\text { numbers) }\end{array}$ & $\begin{array}{l}\text { Branded drug } \\
\text { outlet } \\
\text { (tablets in } \\
\text { numbers) }\end{array}$ & $\begin{array}{l}\text { Generic outlet } \\
\text { (tablets in } \\
\text { numbers) }\end{array}$ \\
\hline 1 & Metformin hydrochloride $500 \mathrm{mg}$ & 300 & 300 & 300 & 300 & 300 \\
\hline 2 & Glibenclamide $5 \mathrm{mg}$ & 300 & 300 & 300 & 300 & 300 \\
\hline 3 & Atenolol $50 \mathrm{mg}$ & $308^{*}$ & 308 & 308 & 308 & 308 \\
\hline 4 & Amlodipine $5 \mathrm{mg}$ & 300 & 300 & 300 & 300 & 300 \\
\hline
\end{tabular}

*Atenolol 50 mg packaged with 14 tablets in each strip, hence $14 \times 22=308$; for remaining all tablets each strip packaged with 15 tablets $15 \times 20=300$. 
2. Chemical composition test: to establish the quantity of the molecule using HPLC instrumental analytical methods. Metformin and atenolol were assayed through the ultraviolet method while glibenclamide and amlodipine were assayed through HPLC.

3. Uniformity of content test: this test is done to confirm the uniformity of contents in the batch. This was carried out by conducting assay on 10 units of dosage individually using the instrumental analytical method. This test was only applicable for medicines weighing $\leq 10 \mathrm{mg}$. Uniformity of content test was done for glibenclamide and amlodipine tablets using HPLC.

4. Uniformity of weight: to check uniformity of weight across all sample tablets.

5. Dissolution tests: medicines were analysed through dissolution tests to evaluate their medicine release pattern. These were performed in the dissolution media for six iterations.

The detailed results of the medicine quality tests are shown in the online supplementary file 1.

\section{Data analysis}

All FGDs and in-depth interviews were tape recorded and transcribed in Kannada and translated into English and imported into NVivo V.9. ${ }^{43}$ The first author completed the initial coding process. During the coding, themes within and across transcripts were identified. After the initial round of coding, the second author reviewed the coding for completeness. Two researchers simultaneously went through the coding tree and the transcripts and identified broad themes. All researchers discussed the emergent themes and finalised the thematic areas. Back translation of the transcripts as well as of the emergent concepts and categories were employed to ensure rigour.

\section{Ethical considerations}

Before each FGD, participants were explained the purpose of the study and were given the study information sheet in Kannada. Informed consent was obtained from each participant. Participants were given the option to stop recording for specific portions or for all the interview if they wished to. All transcripts were anonymised and a no harm principle was followed during the study and in analysis and reporting as well.

\section{RESULTS}

Study results have been provided in two broad sections: section A provides medicine quality test results and section B discusses results of FGDs and IDIs and a conceptual framework illustrating drivers, barriers and trust erosion in the health system.

\section{Section A}

Results of medicine quality tests

1. Identification test: all the four medicines (metformin hydrochloride, gibenclamide, atenolol and amlodipine) from five different sources were found to have positive identification tests. This finding was similar both at the private and government drug testing laboratories.

2. Chemical composition or assay test: all medicines from the five different sources were within the prescribed range (as per IP 2014).

3. Uniformity of content: glibenclamide and amlodipine tablets were found to be within the normal range $(85 \%-115 \%)$ in compliance with the IP 2014.

4. Uniformity of weight: all four medicines were within the respective prescribed range for their weight per unit as per the IP 2014. For example, for metformin $500 \mathrm{mg}$ tablets from each of these five sources, their tested weights at both laboratories was found to be within range ( $\pm 5 \%$ of their average weights).

5. Dissolution test: metformin and amlodipine passed all six iterations as per standard criteria.

The medicine quality tests showed that generic and branded generic medicines' quality of the four key medicines from all four sources were identical to branded medicines' quality and complied to all the prescribed criteria by statutory standards (see online supplementary file 1 ).

\section{Section B}

Trust in medicines and health system: a framework

The themes across the coded portions of the transcripts were: (1) confidence (in provider), (2) loyalty and fidelity, (3) expectations (from provider) and experiences (in care/treatment seeking), and (4) communication (patient-provider) and competence. The interviews and FGDs mainly focused on community perceptions (of medicines and care) and on healthcare delivery (largely in nearby government PHCs). The overall governance of the health system although not an explicit theme explored in the study, emerged as an important element in various interactions. We have summarised our findings across these themes below with illustrative portions of transcripts under those themes.

Trust emerged as an important underlying theme that cut across most of these themes. Hence, a conceptual framework was developed (figure 1). The framework illustrates drivers and barriers in accessing care in public and private facilities. It also shows, from the top, how various factors are responsible for setting the agenda on NCD care at health service delivery levels; from bottom, how the underlying software of health systems (related to trust, norms, values and people's expectations) affects healthcare utilisation and shapes choice of health services (between public and private facilities) and influences access (beyond availability and affordability of care which are most widely studied).

This framework is adapted from the Bigdeli et alframework on access to medicines which seeks to understand the nature of interaction between different levels in health system, starting with individual households and communities at the bottom to the international context at the top, with the layers in between representing health service delivery and the systemic building blocks within 


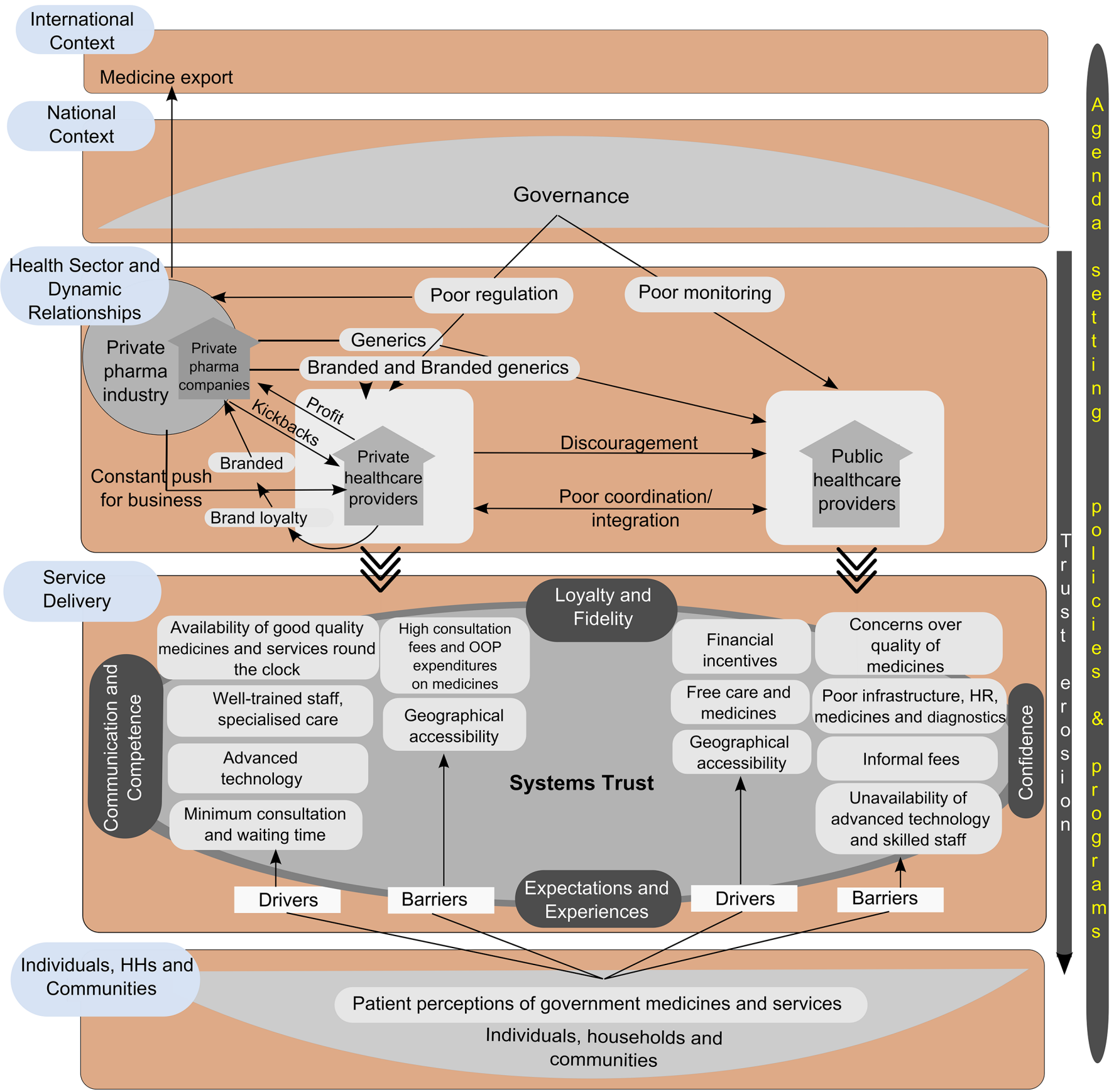

Figure 1 Conceptual framework illustrating drivers and barriers in accessing care in public and private facilities and what influences this. The top two tiers pertain to governance. The middle two tiers pertain to dynamic relationships between different health sector actors and service delivery. The bottom tier pertains to the role of individuals, households and communities. Drivers and barriers of access to the private and public sector are to the left and right of the service delivery block respectively. Trust and the themes that emerged with respect to it are at the centre of the framework. Adapted from 'A system framework on access to medicines- implications for research and policy' by Bigdeli et al. ${ }^{1}$

the governance and public policy architecture of the country. ${ }^{1}$ While these layers are typical of any national health system (within the international context), the relationships between the layers (arrows) and the relative contribution of specific components within these layers could vary from one setting to another. In the current framework, we have illustrated the relationships based on the results from the qualitative data analysis, as well as an understanding of the regulatory context through available literature. For this paper, the framework's five horizontal blocks: international and national contexts, dynamic relationships within the healthcare sector, service delivery and individual/ households/community level, have been used to organise the thematic analysis results and present them. The blocks are briefly described below. Among the blocks, the international and national contexts were not within the scope of our study. 


\section{International context}

The larger global context influences agenda-setting and prioritisation at national levels as well as shapes local research and action agendas through funding priorities. With respect to medicines, the role of international trade relations, medicine and pharmaceutical markets and the global positioning of the NCD care agenda are specifically involved in national agenda setting on NCDs and medicines, in addition to other forces from below.

\section{National context}

Governance and public policy and health system governance shape national and state priorities. In the case of India, the poor use of available regulatory instruments is well known and is a dominant factor in enabling some of the private health sector relationships shown in the framework. In our framework, we identify various relationships (arrows) in the interface between the private pharmaceutical industry and private healthcare providers. In a setting where this interface is better regulated, some of the alignments could shift in favour of the public sector.

\section{Health sector}

The health sector in India is characterised by inadequate and poor governance of both public and private sectors. The private sector is poorly regulated with a focus on return on investment and a frequent and undocumented interface with the private pharmaceutical industry for increased sales and new products. Poor monitoring mechanisms in the public sector and poor coordination between public and private sectors affect healthcare delivery.

\section{Service delivery}

In a system mediated by competitive choice between various types of private providers and financially and geographically relatively accessible public providers, various individual and societal perceptions drive these choices, as illustrated by our thematic analysis results presented below.

\section{Individual and community level}

Patient opinion and perceptions of medicines and government services are often the deciding factor in healthcare choice. With trust at the centre, several themes from our analysis (see below) emerged as drivers of healthcare-seeking and utilisation. Only the last three blocks of the Bigdeli et al framework were explored in our study, that is, (1) individuals and communities, (2) service delivery and (3) health sector. The themes that emerged in these three blocks and the findings under these blocks are described below.

\section{Individual and community level}

Negative perceptions regarding government supplied medicines (unbranded generics) emerged strongly from community interviews. A majority of patients expressed negative opinions regarding the efficacy and quality of medicines. Many patients reported differences in efficacy between 'government medicines' (often generics) compared with branded medicines. The common perception was that they either got partial relief or no relief from symptoms when they took government-supplied (generic) medicines.

Once I had stomach pain, ...from the PHC, it was not cured, then I went to Koratagere (sub district hospital), then to Tumkur government hospital(district hospital), there they gave medicines, it was not cured... then I went to private hospital, there they gave good injection the cost of it was 360 rupees $^{\text {ii }}$ then I felt completely better.(FGD 5)

We work for the whole day and in the evening, sometimes if we have severe pain we go to medical shop (private pharmacy) and take some tablets, and when we swallow it the next day we will be ready again to work, but if we take the tablets of government hospital the stiffness in the joints will be there, it will never go. (FGD 3)

The popular belief was that government supplied medicines were only for minor illnesses like cough, cold or fever and in case of major diseases people ought to rely on private pharmacy (branded) drugs.

Private medical store (private pharmacy) medicines are powerful; now my BP is under control. For the minor illness, we use PHC medicines for major (illnesses) we have to use private medicines (medicines bought from a private pharmacy). (FGD 2)

\section{Service delivery}

\section{Drivers and barriers in accessing healthcare}

Provision of free medicines and services, geographical accessibility and financial incentives for availing some services (reproductive and child health, including through conditional cash transfers) drives poorer households to the public sector.

In the case of the private sector, many providers are concentrated in towns/cities and charge consultation fees resulting in OOP expenditure. Despite expensive care and geographical barriers, people preferred going to private providers.

Let the expenses be more, but we have to take care of our health. For this reason only we go to private hospital. (FGD 3)

Yes, general (government hospital) had admitted me, but the doctors did not see me because it was weekend and a holiday, so I came back to my village and I could not go again since it was Saturday and Sunday and then I went to the hospital but I could not get a token (for entering the patient queue) since there was heavy rush (overcrowding), then I went to a temple and from there I went to Bangalore to Dr. XXX (private sector doctor).... (FGD 4)

Patients reported various positive experiences as possibly driving their choice in favour of private providers. These included availability of trained staff, availability of

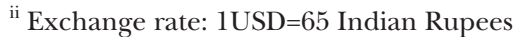


diagnostics, lower consultation and waiting time and availability of what they perceived as good quality (branded and combination) medicines. Often, even poor patients chose the private sector despite higher costs. In general, patients felt that the more one spent in the private facility, the more quality care one got whereas government facilities were only for minor illnesses.

Patients reported several barriers such as unavailability of staff at the time of visit, unavailability of medicines, quality concerns over medicines and unavailability of diagnostic services as influencing their experience and leading them to favour the private sector. In addition, unpleasant experiences like informal fees, negligent attitude of doctors towards patients and providers' perceptions of medicine quality influence patient choice of healthcare facility.

Government health providers' confidence in generic medicines was comparable to patients in terms of efficacy and quality.

I am not sure from where it comes and I (am) also not so sure about the content inside that (generic) tablet. We are also not sure (of) what (is) on the label and what (is) inside the tablet. According to me generic should not be used. (Interview PHC 3)

Generic (Government supplied medicine) will be very low in quality and I am telling this (from) my own experience, if I am ever happen to use my PHC paracetamol (on) my own children I myself put more amount of paracetamol to my child, the quality of medicine is low when compared to private medicines I have also myself experienced the difference in effect. (Interview PHC 2)

\section{Trust in public services}

Various themes related to trust emerged and they are broadly categorised under the following: (1) confidence (in providers and medicines), (2) loyalty and fidelity (in providers), (3) expectations (from providers) and patient experience, (4) communication (doctor-patient) and competence. These are all inter-related and are separately categorised based on the themes that emerged from the analysis of the transcripts.

\section{Confidence}

We observed confidence in providers and services at two levels: one is at the personal level, conditioned by previous experiences or through 'word of mouth', and second at a more abstract institutional level (often conditioned by 'word of mouth'). Patients often referred to kai guna (literally hand quality or touch quality in Kannada referring to the doctor's ability to treat/cure) as being an important determinant of the efficacy of medicines and treatment more generally. The perceived service quality and infrastructure in the private sector and the individualised attention was contrasted by patients with the staff indifference and too short doctor-patient interaction at PHCs.

No madam, they (government facility staff) won't write any details anywhere. They do not have doctor's slip (prescription). They write in a piece of pamphlet (paper) and give, we have to take that to the nurse; she sees that and gives injection. Other than that, they do not have any slip or file or any information. (FGD 2)

There was a doctor by name Dr. xxx, now he is in (another distant) village A. People go from here (to village A) to take treatment from him. He also gives the same tablets as these people, but doctors should have love and affection. Half of our illness goes from that, madam! (FGD 3)

Patients also felt that they were not examined properly in PHCs. This was contrasted to the private sector experience where doctors' attitude towards patients was reported to be an important driver, contributing to their confidence of receiving care, which often overrode considerations of physical distance or cost.

\section{Loyalty and fidelity}

Each patient-doctor interaction tends to condition future healthcare choices made by patients. In the case of NCDs, where long-term or even lifelong care and periodic consultations are needed, patients experienced a sense of loyalty towards a given provider. These relationships could also have implications for future care and could be drivers of choices for government or private care. Medicine quality at government PHCs and hospitals was often a reason provided by private doctors for their care being of superior quality and for patients to purchase medicines from private pharmacies. The feeling of loyalty towards the provider often drove patients to respond positively to such advice even when equivalent medicines or care were available free of cost in government facilities.

I took one injection from (private doctor) he charged me eighty rupees, but the wound healed, I cannot ask him the reason, what I want is (for) me to recover. He said you don't take injection anywhere (government) else so I did not, I took only one injection from him that is all, I was ok. (Patient, FGD 5)

Loyalty was also observed to specific branded medicines, especially NCD medicines. Such brand loyalty was because a trusted doctor had prescribed this specific brand (as opposed to a generic equivalent which was cheaper). Brand loyalty was often an extension of the loyalty to a specific private doctor and not questioned due to fear of breaking trust in the doctor.

If I show government supplied medicines to other private doctor he says, the tablet given there is of less power, so your sugar is not coming (under) control. (FGD 4)

\section{Expectations and experiences}

Patient experiences with medicines and/or health services are crucial in shaping their loyalty, confidence and by extension in their placing trust in a health centre or provider. Expectations of well-packaged 'good' medicines contributed to their relatively better experience in private sector. The general perception that PHCs gave 'same medicines for all diseases' could partly be due 
to generic medicines' lack of investment in packaging, which makes them all appear the same.

They give same medicine for all diseases. How the diseases will be cured? If we go again for medicine we have to pay money. Why should we pay? (FGD 4)

\section{Communication and competence}

These two themes are closely related, especially with respect to how these are understood in patient responses. Most patient perceptions of competence are based on their assessment of communication. Although competence in general refers to ability/skills to provide optimal care or the best possible treatment outcome, in the study, the language in which it was constructed was different. Competence was judged by patients with respect to how well the provider communicated the illness and/or treatment offered, as well as to what extent patients were examined using instruments or given higher-order treatments like injections. Being examined using a stethoscope, or being given an injection during consultation was perceived as a mark of competence, contributing to trust.

When we have problem, we go to government hospital. They don't check anything with stethoscope, they just ask what is my problem and when we say that we have cold, cough and fever, they give some medicines if available, sometimes they don't give injection, but no one will properly check as to what the actual problem is. So, for this reason, we feel why to go to government hospital and we go to private hospitals where they see us properly. (FGD 4)

\section{Health Sector Governance}

Under the current system for quality check of government supplied medicines established by the Central Drug Standard Organisation, if the drug is found to be counterfeit or of poor quality, then the drug may be withdrawn. However, these results are neither displayed in any PHC nor is the system described in a publicly accessible manner at government health facilities. PHC pharmacists recalled instances of delay in communication to withdraw counterfeit medicines.

Most of the medicines pass the test. If it fails, we write a letter. 'This drug is not up to our parameters we will not purchase.' Earlier we used to call back if the drug is not up to the mark. Now we will do the quality test and if it passes we send it for distribution. If we find any drug is not up to the standard, we take it back. (Interview District Level)

Among the private pharmacists, many believed that the quality of medicines, especially generic medicines was not uniform: 'some are good some are not up to the mark'. The delay in receiving notice about drugs not meeting quality standards was also reported by private pharmacists. They reported that they got such information on medicines failing quality standards often after a lot of the stock was sold. Some private pharmacists alleged intentional delay in disseminating such information widely due to corruption/malpractice but did not provide any proof or evidence for this claim. They reported that Indian pharmaceutical industry regulations often did not address quality concerns of generics seriously and due to this, the entire class of generic medicines was blamed.

...what the company is doing is, they will introduce the product to the market, they will give ten thousand rupees to the official and say, sir, whenever you get time you do the quality analysis, I will sell my product, after ending $75 \%$ of that batch, I get the report of good/bad quality, then what is the use of that test. (FGD 4)

\section{DISCUSSION \\ Trust}

Recent efforts at widening the scope of access to medicine frameworks and interventions have called for looking beyond fixing medicines supply chains or improving availability of medicines, to integrating wider systemic elements such as governance, demand-side factors at the community level and more complex health system software elements such as power and trust. ${ }^{1}$ By placing the access to medicines issue as a matter of people's trust in the health system, we stress on the social construction of the problem of access to medicines, while acknowledging the various implementation and managerial barriers to achieving this from the supply side and the governance and health system architectural gaps in promoting access to medicines. ${ }^{445}$

Trust in and relationship with providers as a determinant of health-seeking behaviour has been studied in Cambodia. ${ }^{46}$ In our study too, we found that patients chose their health facility based on their confidence and trust in healthcare providers. In our conceptual framework, we draw on empirical data to integrate the concept of trust in medicines and health services as an underlying systemic element driving patient choice of medicine or provider.

The concept of trust in health systems also stresses on the history (path)-dependent nature of health system reform. The need for systematic and significant investment in promoting and building the reputation of public systems cannot be neglected, while simultaneously investing in popular schemes such as Janaushadhi. The full effects of such schemes may not be realised if sufficient investments in trust-building are not made.

\section{Governance and regulation}

The private health sector in India is extensive and widely used and is often the first point of contact for various illnesses. Government health services in most states on the other hand are grappling with issues such as low investment, poor infrastructure and weak governance. In India's federal system, states are the major regulators of health systems and instances of capture of regulatory institutions by the private sector have been noted.$^{47}$ In such a scenario, the techno-managerial component of access to medicines is dwarfed by the wider systemic gaps 
in regulating the private sector. The findings of our study with respect to private pharmacists' perceptions and people's reliance on the private sector may not be the exercise of a free choice by patients. An act of omission on the part of the government (through weak regulation) could contribute to driving private sector choice by patients. Further in the lack of regulatory checks and balances in favour of adequate patient care in both public and private facilities (eg, through well-enforced standards of care through accreditation mechanisms or licensing), there could be an unintended enabling environment created in favour of more expensive NCD care in the private sector.

Pharmaceutical companies make huge investments in the promotion of branded medicines to private practitioners in India. No such investment goes into the promotion of unbranded generic equivalents in particular. Commissions for increasing prescriptions of expensive proprietary brands (the industry term being kickbacks), long common knowledge among health workers, has recently emerged as an issue in wider public discussion, raising the potential for prioritising stronger regulation. ${ }^{48-50}$

There appears to be an influence on medicine choice mediated through patient-provider loyalty in private healthcare facilities. However, prescribing more expensive branded medicines by private health providers could also be driven by medicine quality perceptions of private health workers, although not grounded in actual quality tests.

\section{Quality of medicines: perceptions versus reality}

Our study finds that the widespread perception of poor medicine quality in government supply chains among health workers (both those in the government and private sectors) and patients is not borne out by an objective assessment of in vitro quality. A study from South Africa which documented patients' and providers' perceptions of generic medicines had similar study findings to our study. ${ }^{41}$ Another South African study documented perceptions of price being used as a proxy for quality. ${ }^{51}$ Such perceptions can have major implications for healthcare utilisation as well as for the continuity of care in public facilities. Doctor-patient communication is one of the vital elements in building trust; our study finds that patients prefer to go to private facilities on account of well-trained staff and a sense of being well cared for.

Patient perceptions that government medicines (generics) are 'less powerful' and that government PHCs are only for 'minor illnesses' undermine some of the foundational elements of comprehensive primary healthcare, which should be a guiding principle of the public health system.

\section{Limitations}

The study tested only a limited set of NCD medicines in a district in Southern Karnataka. Although the study findings could be relevant to many other rural areas in the state, interstate variations in medicine availability and health systems organisation, as well as differing societal perceptions of public services may limit its relevance to other Indian states.

This study was a part of a larger mixed methods study using quantitative household surveys and a theory-driven qualitative component. Since trust in the health system was not a priori the research question driving the larger study, there was no effort made to measure or understand the multiple dimensions and levels at which trust operates. The study was restricted to the themes that emerged in qualitative inquiry based on identifying barriers to improving access to medicines at the local health system level and reports the results around trust in relation to this question.

\section{CONCLUSION}

Our study shows that patients' and healthcare providers' perception have major implications for accessing health services in addition to availability and affordability of care. Policies and programmes focused on improving medicine availability, especially those centred on making generic medicines widely available need to invest in building trust in medicine quality (as well as care) in government health facilities. In addition, investment in the design of context-appropriate packaging for generic medicines is also important. Techno-managerial interventions focusing on improving services (or medicine availability) at PHCs need to consider the wider societal perceptions of these services in their roll-out.

Acknowledgements This research was supported by the Alliance for Health Policy and Systems Research, World Health Organization, with funding from DFID. The authors would like to thank the Tumkur district health team and the Directorate of Health and Family Welfare, Government of Karnataka for their support and encouragement. Anita Kotwani and other participants at the tools finalisation workshop in Bangalore helped with finalising the tools for facility survey. The authors sincerely thank S M Sadhana of Karnataka Health Systems Resource Centre for helping in testing of medicines and other technical inputs. The authors thank N Devadasan for critical inputs into the design and conceptualisation of the study.

Contributors PA and PNS were involved in the conception and design of the study. Field work, lab testing and initial analysis was done by PA, MKP, CMG, SB and MAE. MAE and PA were involved in initial analysis of the qualitative data, MAE reviewed and finalised the qualitative findings. PA wrote the first draft of the manuscript with review and addition by PNS and ZCS. All authors contributed to interpretation of findings and preparing, reading, revising and approving the manuscript.

Funding This study was funded by the Alliance for Health Policy and Systems Research, World Health Organization, Geneva.

Disclaimer The author(s) is(are) staff member(s) of the World Health Organization. The author(s) alone is(are) responsible for the views expressed in this publication and they do not necessarily represent the views, decisions or policies of the World Health Organization. ZCS is a staff member of WHO. He is himself alone responsible for the views expressed in the Article, which do not necessarily represent the views, decisions or policies of WHO.

Competing interests ZCS is a staff member of the Alliance for Health Policy and Systems Research, WHO that funded for this study.

Ethics approval Ethics clearance was obtained from the WHO Ethics Review Committee as well as from the and Institutional Ethics Committee of the Institute of Public Health, Bangaluru. Before proceeding with data collection, permission in writing was sought from the Department of Health and Family Welfare, Government of Karnataka.

Provenance and peer review Not commissioned; internally peer reviewed.

Data sharing statement No additional data are available. 
Open Access This is an open access article distributed under the terms of the Creative Commons Attribution-NonCommercial IGO License (CC BY-NC 3.0 IGO), which permits use, distribution, and reproduction for non-commercial purposes in any medium, provided the original work is properly cited. In any reproduction of this article there should not be any suggestion that WHO or this article endorse any specific organization or products. The use of the WHO logo is not permitted. This notice should be preserved along with the article's original URL. See:https:// creativecommons.org/licenses/by-nc/3.0/igo

(c) World Health Organization [2018]. Licensee BMJ.

\section{REFERENCES}

1. Bigdeli M, Jacobs B, Tomson G, et al. Access to medicines from a health system perspective. Health Policy Plan 2013;28:692-704.

2. Jack A. "World's pharmacy" faces new challenges from Western drug companies. BMJ 2012;345:e6207.

3. Ministry of chemicals and fertilizers. Annual report 2014-15. New Delhi, 2015.

4. Maiti R, Bhatia V, Padhy BM, et al. Essential medicines: an Indian perspective. Indian J Community Med 2015;40:223.

5. Bhargava A, Kalantri SP. The crisis in access to essential medicines in India: key issues which call for action. Indian J Med Ethics 2013;10:86-95.

6. Shahrawat R, Rao KD. Insured yet vulnerable: out-of-pocket payments and India's poor. Health Policy Plan 2012;27:213-21.

7. Planning Commission of India. High level expert group report on universal health coverage for India. New Delhi, 2011.

8. Sundararaman T, Muraleedharan VR, Sick F. Paying the price: NSS 71 st round on morbidity and costs of healthcare. Econ Polit Wkly 2015;L:17-20.

9. Bhojani U, Thriveni B, Devadasan R, et al. Out-of-pocket healthcare payments on chronic conditions impoverish urban poor in Bangalore, India. BMC Public Health 2012;12:990.

10. Berman P, Ahuja R, Bhandari L. The impoverishing effect of healthcare payments in india: new methodology and findings. Econ Polit Wkly 2010;45:65-71.

11. Devadasan N, Ghosh S, Nandraj S, et al. Monitoring and evaluating progress towards Universal Health Coverage in India. PLoS Med 2014;11:e1001697.

12. Directorate General of Health Services. Indian Public Health Standards (IPHS) guidelines for primary health centres revised 2012. New Delhi, 2012. http://nhm.gov.in/images/pdf/guidelines/iphs/iphsrevised-guidlines-2012/primay-health-centres.pdf

13. Nightingale SL. Promotional practices of pharmacy benefits management companies. JAMA 1998;279:645.

14. Tadeg $\mathrm{H}$, Berhane Y. Substandard and counterfeit antimicrobials: recent trends and implications to key public health interventions in developing countries. East Afr J Public Health 2012;9:85-9.

15. Benton D, Williamson L. Fake medicines are everybody's business. Aust Nurs Midwifery J 2014;21:26.

16. Bruhn C. [The fight against counterfeit drugs]. Dtsch Med Wochenschr 2013;138:2396-7.

17. 't Hoen E, Pascual F. Viewpoint: Counterfeit medicines and substandard medicines: Different problems requiring different solutions. J Public Health Policy 2015;36:384-9.

18. Liberman J. Combating counterfeit medicines and illicit trade in tobacco products: minefields in global health governance. J Law Med Ethics 2012;40:326-47.

19. Taverriti-Fortier C, Pape E, Scala-Bertola J, et al. Trafic de faux médicaments : panorama 2014. Thérapie 2015;70:455-64.

20. Mackey TK, Liang BA, York P, et al. Counterfeit drug penetration into global legitimate medicine supply chains: a global assessment. Am J Trop Med Hyg 2015;92:59-67.

21. Travasso C. Counterfeit and substandard drugs in India may be smaller problem than claimed, say government findings. BMJ 2014;348:960

22. Harris G. Medicines made in India set off safety worries: New York Times, 2014

23. Subramanya R. India's generic drug industry has a maggi problem. Foreign Policy Mag, 2015. http://foreignpolicy.com/2015/06/10/ india-maggi-generic-drugs-modi-pharma/

24. Mathur A, Bate R, Jin GZ. India Must Fix Its Drug Quality Problem. Forbes, 2014. https://www.forbes.com/sites/theapothecary/2014/ 09/17/india-must-fix-its-drug-quality-problem/\#7502290a70b3

25. Kazmin A. Indian drugs: not what the doctor ordered: Financial Times, 2015. https://www.ft.com/content/de0ca3f4-5581-11e597e9-7f0bf5e7177b
26. Ravinetto RM, Dorlo TP, Caudron JM, et al. The global impact of Indian generics on access to health. Indian J Med Ethics 2013;10:118-20.

27. Johnston A, Holt DW. Substandard drugs: a potential crisis for public health. Br J Clin Pharmacol 2014;78:218-43.

28. Dunne SS, Dunne CP. What do people really think of generic medicines? A systematic review and critical appraisal of literature on stakeholder perceptions of generic drugs. BMC Med 2015;13:173

29. Cockburn R, Newton PN, Agyarko EK, et al. The global threat of counterfeit drugs: why industry and governments must communicate the dangers. PLoS Med 2005;2:e100.

30. Newton PN, Green MD, Fernández FM. Impact of poor-quality medicines in the 'developing' world. Trends Pharmacol Sci 2010;31:99-101.

31. Hall MA, Dugan E, Zheng B, et al. Trust in physicians and medical institutions: what is it, can it be measured, and does it matter? Milbank Q 2001;79:613-39.

32. Robinson CA. Trust, health care relationships, and chronic illness: a theoretical coalescence. Glob Qual Nurs Res 2016;3:2333393616664823.

33. Phillips-Salimi CR, Haase JE, Kooken WC. Connectedness in the context of patient-provider relationships: a concept analysis. $J$ Adv Nurs 2012;68:230-45.

34. Engelgau MM, Karan A, Mahal A. The Economic impact of Noncommunicable Diseases on households in India. Global Health 2012;8:9.

35. Bhojani U, Beerenahalli TS, Devadasan R, et al. No longer diseases of the wealthy: prevalence and health-seeking for self-reported chronic conditions among urban poor in Southern India. BMC Health Serv Res 2013;13:306.

36. Kotwani A. Commentary: will generic drug stores improve access to essential medicines for the poor in India? J Public Health Policy 2010;31:178-84.

37. Jayaraman K. Troubles beset 'Jan Aushadhi' plan to broaden access to generics. Nat Med 2010;16:350.

38. Singal GL, Nanda A, Kotwani A. A comparative evaluation of price and quality of some branded versus branded-generic medicines of the same manufacturer in India. Indian J Pharmacol 2011;43:131-6.

39. Kotwani A. Psychiatric medicines in India: why public healthcare facilities and a thriving generics industry cannot assure access and affordability. Int Psychiatry 2012;9: 34 - 36

40. Kotwani A, Ewen M, Dey D, et al. Prices \& availability of common medicines at six sites in India using a standard methodology. Indian $J$ Med Res 2007:125:645-54.

41. Patel A, Gauld R, Norris P, et al. Quality of generic medicines in South Africa: perceptions versus reality - a qualitative study. BMC Health Serv Res 2012;12:297.

42. Prashanth NS, Elias MA, Pati MK, et al. Improving access to medicines for non-communicable diseases in rural India: a mixed methods study protocol using quasi-experimental design. BMC Health Serv Res 2016;16:421.

43. QSR International Pty Ltd. NVivo qualitative data analysis software. 2012.

44. Sheikh K, George A, Gilson L. People-centred science: strengthening the practice of health policy and systems research. Health Res Policy Syst 2014;12:19.

45. Sheikh K, Ranson MK, Gilson L. Explorations on people centredness in health systems. Health Policy Plan 2014;29:ii1-5.

46. Ozawa S, Walker DG. Comparison of trust in public vs private health care providers in rural Cambodia. Health Policy Plan. In Press 2011;26:i20-9.

47. Sheikh K, Saligram PS, Hort K. What explains regulatory failure? Analysing the architecture of health care regulation in two Indian states. Health Policy Plan 2015:30:39-55.

48. Berger D. Corruption ruins the doctor-patient relationship in India BMJ 2014;348:93169.

49. Huss R, Green A, Sudarshan $\mathrm{H}$, et al. Good governance and corruption in the health sector: lessons from the Karnataka experience. Health Policy Plan 2011;26:471-84.

50. Prashanth NS. Regulator needed to end doctors' unethical practice. Deccan Her, 2014. http://www.deccanherald.com/content/422186/ archives.php

51. Patel A, Gauld R, Norris P, et al. "This body does not want free medicines": South African consumer perceptions of drug quality. Health Policy Plan 2010;25:61-9. 